\title{
Balancing the risks and benefits of parenteral nutrition for preterm infants: can we define the optimal composition?
}

\author{
Nicholas D Embleton, ${ }^{1,2}$ Colin Morgan, ${ }^{3}$ Caroline King ${ }^{4}$
}

\begin{abstract}
${ }^{1}$ Newcastle Neonatal Service, Newcastle Hospitals NHS Foundation Trust, Newcastle, UK

${ }^{2}$ Institute of Health and

Society, Newcastle University, Newcastle, UK

${ }^{3}$ Neonatal Intensive Care Unit, Liverpool Women's Hospital,

Liverpool, UK

${ }^{4}$ Neonatal Units, Imperial

College Healthcare NHS Trust, London, UK
\end{abstract}

\section{Correspondence to} Dr Nicholas D Embleton, Newcastle Neonatal Service, Newcastle Hospitals NHS Foundation Trust, Newcastle NE1 4LP, UK:

Nicholas.embleton@ncl.ac.uk

Received 15 November 2013 Revised 21 April 2014 Accepted 23 May 2014 Published Online First 12 June 2014

\section{ABSTRACT}

Nutrient intakes in preterm infants are frequently inadequate and are associated with worse neurodevelopmental outcome. Preterm infants take time to establish enteral intakes, and parenteral nutrition (PN) is now an integral component of care. Despite this, the evidence base for PN intakes is extremely limited. There remains uncertainty over safe initial and maximum amounts of macronutrients, and the optimal amino acid and lipid composition. Studies have tended to focus on short-term growth measures and there are few studies with long-term follow-up. There may be a tradeoff between improving cognitive outcomes while minimising metabolic harm that means determining the optimal regimen will require long-term follow-up. Given the importance of appropriate nutrition for long-term metabolic and cognitive health, and the associated healthcare costs, optimising the composition of PN deserves to be seen as a research priority in neonatal medicine.

Parenteral nutrition (PN) is established as standard-of-care for preterm infants, but despite its widespread use, the evidence base for the optimal composition is extremely limited. ${ }^{1}$ A recent National Confidential Enquiry into Patient Outcome and Death enquiry into neonatal PN highlighted a diverse range of practices, many of which were considered to be substandard across the UK. ${ }^{2}$ This may, in part, reflect uncertainty around intake recommendations in the early postnatal period. Preterm infants have limited nutrient stores, with strong evidence that nutrient intakes in early postnatal life relate to cognitive outcomes. ${ }^{3}$ The commonest use of neonatal $\mathrm{PN}$ in preterm infants is as 'bridging nutrition' while enteral nutrition is established, but it is also an essential part of management where enteral feeding is not possible, for example, in infants with necrotising enterocolitis (NEC). The wide range in requirements between, for example, a 24-week infant establishing feeds, and a growth-restricted 32-week infant following NEC make defining a single optimal composition for 'preterm infants' impossible. Nevertheless, the aim of this article is to describe the clinical challenges of determining optimal PN intakes, particularly macronutrients, such as protein, lipid and carbohydrate, in otherwise stable, preterm infants.

The evolution of neonatal PN in the late $1960 \mathrm{~s}^{4}$ required several technical challenges to be overcome. ${ }^{5}$ Since then, dramatic advances in neonatal care have meant that infants weighing $500-750 \mathrm{~g}$ frequently survive, and PN administration is now a daily occurrence in most neonatal intensive care units (NICU). Unfortunately, improvements in the evidence base for PN intakes have failed to match the success of increased survival. Although the nutrient requirements to enable growth to approximate that of the in utero fetus are well described, ${ }^{6}$ there remain substantial challenges in terms of assessing growth in clinical practice (which is more complex than simply weight gain) and defining the optimal rate of growth ex utero which may not be the same as that when in utero. ${ }^{7}$ Systematic reviews of PN have shown a benefit on time to regain birth weight and early measures of growth, ${ }^{8}$ but there are no current controlled trial data to show a longterm benefit on growth, metabolic or cognitive outcomes.

While many observational studies suggest that higher rates of weight gain ${ }^{9}$ or nutrient intakes ${ }^{3}$ are associated with improved neurodevelopmental outcomes, these studies may lack adequate adjustment for confounders, and are at risk from reverse causation. While there are some limited, randomised, controlled trial (RCT) data to suggest that higher enteral nutrient intakes improve cognition in adolescence, ${ }^{10}$ there are no equivalent data for parenteral intakes. Nevertheless, these strong links between early nutrient intakes and later outcome, suggest that suboptimal provision of parenteral nutrients in early life is likely to have life-long adverse cognitive impacts. A recent RCT has shown a benefit of higher parenteral nutrient intakes on head growth, ${ }^{11}$ but longer-term follow-up will be needed to determine if this results in functional benefit. While growth (or proxy measures such as weight gain) is an important measure of health status for preterm infants, it has many shortfalls as an outcome measure in itself. The optimal pattern of growth needs to balance the potentially competing concerns of cognitive benefits versus the risks of adverse metabolic programming.

Most extremely preterm infants take at least 10-14 days to tolerate full enteral nutrition, so the composition of a typical neonatal PN regimen must be designed to complement any enteral intake, and when combined, aim to provide all essential nutrients during this period. Because infants receive nutrients via the parenteral and enteral route in the early postnatal period, trial designs aiming to determine the effect of early parenteral or enteral nutrition are necessarily complex. The postnatal age and speed of increase of PN that results in the optimal balance of risks and benefits such as line-associated sepsis from prolonged PN, and increased feed intolerance or NEC from faster enteral feeds is not 
clear, but is currently being examined in RCTs, such as the Speed of Increasing milk Feeds Trial (SIFT (http://www.npeu.ox. ac.uk/sift)). Additionally, given the multitude of nutrients that need to be provided by PN, progress would be painstakingly slow if a pharmaceutical-type RCT approach to each and every nutrient was adopted. Even then, nutrient interdependence will mean that the first limiting nutrient will set the ceiling for outcomes: a null finding for single nutrient enhancement may be obtained because of inadequate provision of other nutrients or cofactors. Currently used neurodevelopmental tools (such as Bayley Scale of Infant Development) provide important data on global outcome, but may lack the precision to detect important differences in the more specific cognitive domains likely to be affected by individual nutrients. ${ }^{12}$

\section{PROTEIN AND AMINO ACIDS}

At 24 weeks gestation, a fetus weighing $500 \mathrm{~g}$ is composed of $\sim 90 \%$ water with only $\sim 50 \mathrm{~g}$ of 'dry' tissue. ${ }^{13}$ Extremely preterm infants have no energy stores as such, and must catabolise body protein to meet energy requirements if these are not met by the diet. The rapidity with which malnutrition occurs is dramatic, and birth of an extremely preterm infant must be seen as a nutritional emergency. Inevitable nitrogen losses (in urine, faeces, skin cells and secretions) are equivalent to $\sim 1 \mathrm{~g} / \mathrm{kg} /$ day of protein in a preterm infant, but may be $50 \%$ higher in those born $<28$ weeks gestation..$^{14}$ The predicted daily protein accretion of a fetus at 28 weeks gestation is $\sim 2 \mathrm{~g} / \mathrm{kg},{ }^{13}$ meaning that an intake of at least $3-3.5 \mathrm{~g} / \mathrm{kg}$ (protein or amino acid (AA) equivalent) is needed to promote protein accretion and allow for obligatory losses, if lean mass accretion is to proceed at a rate approximately the same as the in utero fetus. Higher intakes may be needed in the smallest infants and/or following a catabolic episode, or if catch-up growth is appropriate. Considering that obligatory protein losses in an extremely preterm infant are $<1.5 \mathrm{~g} / \mathrm{kg} /$ day, and that $\sim 2 \mathrm{~g} / \mathrm{kg} /$ day protein are accreted in utero, it is possible to estimate that a preterm infant's lean mass will be less than $90 \%$ of the equivalent in utero fetus after just $48 \mathrm{~h}$, unless exogenous AA are administered.

A series of studies in the 1980s and 1990s focused on nitrogen balance in the first week of life at differing levels of macronutrient intakes and broadly support AA intakes of $3-3.5 \mathrm{~g} / \mathrm{kg} /$ day once full PN is established, if nitrogen retention similar to the in utero fetus is the primary objective. ${ }^{15}$ More recent studies confirmed these data, ${ }^{16} 17$ but there are now some data to support even higher intakes $(3.5-4 \mathrm{~g} / \mathrm{kg} /$ day $)$ within the first week. ${ }^{11}{ }^{18-20}$ Many of the earlier studies used metabolisable energy intakes lower $(30-70 \mathrm{kcal} / \mathrm{kg} /$ day $)$ than are commonly used now, although the optimal protein-energy ratio has yet to be well defined. While high AA infusions commencing immediately after birth $(>3 \mathrm{~g} / \mathrm{kg} /$ day $)$ may mimic the observed high AA oxidation rate seen in utero, ${ }^{21}$ preterm babies must function without the help of the placenta to remove potentially toxic metabolites. A recent RCT data showed that $3.6 \mathrm{~g} / \mathrm{kg} /$ day gave no additional advantage to $2.4 \mathrm{~g} / \mathrm{kg} /$ day in the first $48 \mathrm{~h}$ with respect to nitrogen accretion, but was associated with more metabolic imbalances, ${ }^{18}$ while another showed improved head growth on $\sim 2 \mathrm{~g} / \mathrm{kg} /$ day during the first 2 days increasing to $3.8 \mathrm{~g}$ by day $5 .{ }^{11}$

Splanchnic metabolism is important, but AA provided in PN avoid hepatic and splanchnic 'first pass' metabolism. ${ }^{22}$ Individual AA requirements are poorly defined, with evidence that some 'non-essential' AA are 'conditionally essential' in preterm infants including arginine, glutamine, glycine, proline, taurine, and tyrosine. ${ }^{22}{ }^{23}$ Without knowledge of individual AA requirements, it may not be possible to define the optimal AA composition that best meet needs. ${ }^{24}$

There are additional practical challenges in AA delivery, such as solubility and precipitation problems associated with certain AA such as tyrosine and cysteine that will influence optimal PN composition. ${ }^{25}$ Current commercially available AA solutions appear to result in acceptable levels of nitrogen retention and plasma AA profiles, although the plasma concentrations of many conditionally essential AA are frequently lower than in utero references. ${ }^{26}{ }^{27}$ However, there is substantial debate around the appropriate plasma AA reference for a preterm infant receiving PN in terms of safety and efficacy: are in utero or cord blood levels appropriate, or is the plasma AA profile of a healthy breastfed infant a more appropriate reference? One small recent study suggested an association between raised concentrations of $\mathrm{AA}$ and worse developmental outcome. ${ }^{28}$ Although the focus of this article is on PN nutrient composition, several studies indicate that achieving AA intakes that improve growth are not just dependent on PN AA composition, but also influenced by the use of clear nutritional strategies, standardised and/or concentrated solutions and PN service organisation.

\section{ENERGY}

Although difficult to precisely measure, it can be extrapolated from published data that resting energy expenditure is likely to be around $50-60 \mathrm{Kcal} / \mathrm{kg} /$ day in most stable growing preterm infants, although it will be higher in those with additional demands from coexisting morbidities such as sepsis. ${ }^{29}$ To enable growth, at least $100 \mathrm{kcal} / \mathrm{kg} /$ day will be needed for exclusively $\mathrm{PN}$-fed babies although requirements are likely to increase as the proportion of enteral nutrition increases. The energy cost of growth depends on the precise tissue accreted and cannot be directly determined in preterm infants. Stable isotope studies have demonstrated the highly dynamic nature of protein turnover in preterm infants and show that $\sim 5 \mathrm{~g}$ protein is synthesised and catabolised for every $1 \mathrm{~g}$ protein that is finally accreted. ${ }^{30-32}$ This high level of protein synthesis and catabolism demands high protein and energy intakes.

\section{INTRAVENOUS LIPID}

Intravenous lipid provides a concentrated source of energy, a delivery mechanism for fat-soluble vitamins, and also provides essential fatty acids (EFA). Although the amount required to prevent EFA deficiency is quite low $(<0.5 \mathrm{~g} / \mathrm{kg} /$ day $)$, the requirements for optimal neurodevelopmental outcomes are likely to be considerably higher. Concerns regarding lipid deposition in the lungs, and the vasoactive effects of hyperperoxides and proinflammatory cytokines on pulmonary vascular function led to more cautious introduction in the past. While many authorities recommend commencement at $1-2 \mathrm{~g} / \mathrm{kg} / \mathrm{day}$ on the first day, increasing to $3-4 \mathrm{~g} / \mathrm{kg} /$ day where $\mathrm{PN}$ is the sole source of nutrition, there are no data demonstrating clear long-term benefit. ${ }^{1} 33$ Increased lipid supply may improve early nitrogen retention, ${ }^{34}$ but there are limited data at the upper end of the intake range $(3-4 \mathrm{~g} / \mathrm{kg})$, and no reliable data for intakes $>4 \mathrm{~g} / \mathrm{kg} /$ day. Systematic reviews suggest there is no disadvantage to commencement before day 5 , but few studies compared very early initiation immediately after birth to $48 \mathrm{~h}$ of age, that is now commonly practiced. ${ }^{34} 35$ There is no consensus about whether there is a need to monitor for the presence of lipaemia, or raised levels of either cholesterol or triglycerides, or the acceptable upper limit that should be tolerated in parenterally fed infants. 
Currently available intravenous lipid solutions were not designed with the objective of meeting the needs of extremely preterm infants. The most widely used products are produced from soybean oil and have a long track record of short-term safety, but do not provide the optimal blend of fatty acids. Newer lipids using olive oil, or a combination of soybean oil, medium-chain triglycerides, olive oil and fish oil are now increasingly used. ${ }^{34} 3637$ Studies in older children suggest that these newer formulations might be advantageous, with those containing fish oil appearing to result in a lower incidence of liver inflammation and more appropriate fatty acids profiles. ${ }^{36} 38$ However an excess of eicosapentaenoic acid compared to arachidonic acid, as found in some of these new fish oil-based emulsions, has been associated with reduced growth when fed enterally to preterm infants. ${ }^{39}$ Currently, there are no long-term outcome data on preterm infants receiving newer lipid formulations. These products arose because of a desire to reduce the adverse proinflammatory hepatic effects seen in adults (and children), so while there may be a potential cognitive advantage to preterm infants of these lipids, this was not the driver for innovation. Like many areas of 'medicines' research, neonatal practice appears to lag behind.

\section{MONITORING OF NUTRIENT INTAKES}

There are no neonatal studies that help determine the optimal monitoring regimen for $\mathrm{PN}$, but frequent electrolyte and glucose monitoring is important. Hyperglycaemia is common, but there appears to be no benefit in routine basal insulin administration. ${ }^{40}$ Additionally, the glucose threshold at which insulin is started (that balances the risks of insulin with any benefits) has not been defined, nor have the relative benefits of insulin been compared with alternate strategies such as decreasing carbohydrate intake. There is increasing recognition of a link between early weight gain, levels of IGF-1, and retinopathy of prematurity that suggest increased AA and glucose intakes may be of benefit to brain growth. ${ }^{41}$ Whether insulin has a role in modulating these processes remains to be determined.

Measurement of phosphate over the first few days of PN is not common but is likely to be important: phosphate is an important substrate for muscle function, and a component of lean tissue. It seems possible that some babies may need ventilatory support in the first few days simply because of inadequate phosphate levels. A recent study suggested that higher AA intakes without adequate phosphate supply, especially in infants who were growth restricted in utero, might cause a metabolic derangement similar to the 're-feeding' syndrome seen in adults following starvation. ${ }^{43}$ It is not possible to assess the adequacy of PN AA intakes (ie, 'protein' supply) in individual patients: plasma AA measurement is expensive and there is no agreed reference, total serum protein concentration does not reflect anabolism, albumin has a half-life of several weeks, and urea is not a sensitive indicator of nitrogen intake over the first few days. Proteins with shorter half-lives (eg, retinol-binding protein) are not measured in clinical practice but might be useful indicators of short-term protein status. Acidosis or hyperammonaemia are rarely observed using modern PN AA formulations.

\section{BALANCING THE RISKS}

Determining the optimal nutrient composition of $\mathrm{PN}$ requires clinicians to balance multiple competing risks for several constituents in a situation where the evidence base is extremely poor. PN composition may be associated with manufacturing risks: solutions can become contaminated with toxins such as aluminium leached from glass vials containing calcium gluconate resulting in worse neurodevelopmental ${ }^{44}$ and bone outcomes in adolescents. ${ }^{45}$ There are multiple other potential adverse effects as a consequence of PN composition: for example, one study has shown an association between raised cholesterol levels in early postnatal life and aortic stiffness in later life. ${ }^{46}$ While there is general agreement that most preterm infants $<1500 \mathrm{~g}$ birth weight are likely to benefit, the precise cutoffs at which the risks outweigh the benefits have yet to be determined (see table 1).

Because of the problems associated with observational studies, many of these uncertainties can only be resolved with large RCTs and long-term follow-up of metabolic, growth and cognitive outcomes that attempt to quantify the competing risks and benefits. In the absence of RCT data, standardised PN regimens with robust audit, and use of large-scale databases that include long-term developmental outcome may be used to refine practice. There are several areas of uncertainty, some of which we have listed in table 2 . The wide variability in current practice reflects a lack of evidence on which to base robust guidelines, and the fact that most current recommendations are based on 'expert opinion'. Given that PN is a critical determinant of survival and long-term outcome, carries with it substantial healthcare costs, and is administered to tens of thousands of preterm infants worldwide every year, this uncertainty reflects a woeful lack of well-designed research studies.

Table 1 Examples of risk-benefit 'tradeoffs' associated with parenteral nutrition composition

\begin{tabular}{|c|c|}
\hline $\begin{array}{l}\text { Component or } \\
\text { issue }\end{array}$ & Example of risks and benefits \\
\hline Minerals & Contamination (eg, aluminium) and solubility issues (eg, calcium and phosphate) limit mineral supply, and also affect tonicity \\
\hline Amino acids & Inadequate supply of essential or semiessential amino acids may prevent optimal tissue growth, but high peak levels may cause neuronal damage \\
\hline Lipids & $\begin{array}{l}\text { Lipids provide higher caloric intakes than could be provided by carbohydrates alone, but raised circulating triglyceride and lipid levels may increase } \\
\text { later metabolic and cardiovascular risk }\end{array}$ \\
\hline Carbohydrate & $\begin{array}{l}\text { Hyperglycaemia is common, but decreasing dextrose intake limits energy intake, and insulin therapy is associated with risks and may not promote } \\
\text { anabolism }\end{array}$ \\
\hline Osmolality & $\begin{array}{l}\text { Hyperosmolar solutions require central venous catheters (CVC) but these increase the risk of sepsis. Peripheral administration avoids the risks of CVCs, } \\
\text { but increases the risks of skin damage, pain and scarring }\end{array}$ \\
\hline $\begin{array}{l}\text { Monitoring } \\
\text { frequency }\end{array}$ & $\begin{array}{l}\text { Regular electrolyte and glucose measurement enables fine tuning of intakes, but may be associated with pain/discomfort, anaemia, and skin } \\
\text { infections }\end{array}$ \\
\hline Standardised bags & $\begin{array}{l}\text { Cost savings and safety are improved by use of standard bags, but these limit the ability to tailor to individual infant needs, especially when fluid } \\
\text { volumes are limited }\end{array}$ \\
\hline
\end{tabular}


Table 2 Examples of current uncertainties and potential ways forward

\section{Area of uncertainty}

Safe limits for starting amino acid, carbohydrate and lipid supply Formulations and intakes that improve neurodevelopmental outcome

Formulations and intakes that improve neurocognitive outcome but minimise metabolic harm

Optimal monitoring regimen to determine tolerance and safety Optimal composition for range of standard neonatal PN bags

\section{Potential study}

RCT with long-term follow-up into infancy

RCT with head growth data, MRI assessment and/or developmental outcome in infancy and early childhood

RCT with long-term follow-up into later life including detailed neurocognitive and metabolic assessment

Observational studies matched with long-term outcome using collaborative databases Standardisation across clinical networks combined with collaborative audit

$\mathrm{PN}$, parenteral nutrition, $\mathrm{RCT}$, randomised controlled trial.

Contributors All three authors are responsible for the paper, and have participated in the concept and design, drafting or revising, and have approved this manuscript as submitted.

\section{Competing interests None.}

Provenance and peer review Commissioned; externally peer reviewed.

\section{REFERENCES}

1 Lapillonne A, Carnielli VP, Embleton ND, et al. Quality of newborn care: adherence to guidelines for parenteral nutrition in preterm infants in four European countries. BMJ Open 2013;3:e003478.

2 Mason DG, Puntis JW, McCormick K, et al. Parenteral nutrition for neonates and children: a mixed bag. Arch Dis Child 2011;96:209-10.

3 Stephens BE, Walden RV, Gargus RA, et al. First-week protein and energy intakes are associated with 18-month developmental outcomes in extremely low birth weight infants. Pediatrics 2009;123:1337-43.

4 Wilmore DW, Dudrick SJ. Growth and development of an infant receiving all nutrients exclusively by vein. JAMA 1968;203:860-4.

5 Dudrick SJ. History of parenteral nutrition. J Am Coll Nutr 2009;28:243-51.

6 Tsang R, Uauy R, Zlotkin S, et al. eds. Nutritional needs of the preterm infant: scientific basis and practical guidelines. Digital Educational Publishing, 2005.

7 Vasu V, Modi N. Assessing the impact of preterm nutrition. Early Hum Dev 2007;83:813-18

8 Moyses HE, Johnson MJ, Leaf AA, et al. Early parenteral nutrition and growth outcomes in preterm infants: a systematic review and meta-analysis. Am J Clin Nutr 2013;97:816-26

9 Ehrenkranz RA, Dusick AM, Vohr BR, et al. Growth in the neonatal intensive care unit influences neurodevelopmental and growth outcomes of extremely low birth weight infants. Pediatrics 2006;117:1253-61.

10 Isaacs EB, Gadian DG, Sabatini $S$, et al. The effect of early human diet on caudate volumes and IQ. Pediatr Res 2008;63:308-14.

11 Morgan C, McGowan P, Herwitker S, et al. Postnatal head growth in preterm infants: a randomized controlled parenteral nutrition study. Pediatrics 2014;133:e120-8.

12 Colombo J, Carlson SE. Is the measure the message: The BSID and nutritional interventions. Pediatrics 2012;129:1166-67.

13 Ziegler EE, O'Donnell AM, Nelson SE, et al. Body composition of the reference fetus. Growth 1976:40:329-41.

14 Denne SC. Regulation of proteolysis and optimal protein accretion in extremely premature newborns. Am I Clin Nutr 2007;85:621S-4S.

15 Embleton ND. Optimal protein and energy intakes in preterm infants. Early Hum Dev 2007;83:831-7.

16 te Braake FW, van den Akker $\mathrm{CH}$, Wattimena DJ, et al. Amino acid administration to premature infants directly after birth. [see comment]. J Pediatr 2005;147:457-61.

17 Ibrahim HM, Jeroudi MA, Baier RJ, et al. Aggressive early total parental nutrition in low-birth-weight infants. J Perinatol 2004;24:482-6.

18 Vlaardingerbroek H, Vermeulen MJ, Rook D, et al. Safety and Efficacy of Early Parenteral Lipid and High-Dose Amino Acid Administration to Very Low Birth Weight Infants. J Pediatr 2013;163:638-44.e1-5.

19 Senterre T, Rigo J. Reduction in postnatal cumulative nutritional deficit and improvement of growth in extremely preterm infants. Acta Paediatr 2012;101:e64-70.

20 Cormack BE, Bloomfield FH. Increased protein intake decreases postnatal growth faltering in ELBW babies. Arch Dis Child Fetal Neonatal Ed 2013;98:F399-404.

21 Hay WW, Thureen P. Protein for preterm infants: how much is needed? How much is enough? How much is too much? Pediatr Neonatol 2010;51:198-207.

22 Vlaardingerbroek $\mathrm{H}$, van den Akker CHP, et al. Amino acids for the neonate: Search for the ideal dietary composition. NeoReviews 2011;12:e506-e16.

23 Moe-Byrne T, Wagner JV, McGuire W. Glutamine supplementation to prevent morbidity and mortality in preterm infants. Cochrane Database Syst Rev 2012;3:CD001457.

24 Morgan C. Early amino acid administration in very preterm infants: Too little, too late or too much, too soon? Semin Fetal Neonatal Med 2013:18:160-5.
25 Van Goudoever JB, Sulkers EJ, Timmerman M, et al. Amino acid solutions for premature neonates during the first week of life: the role of N-acetyl-L-cysteine and N-acetyl-L-tyrosine. JPEN J Parenter Enteral Nutr 1994;18:404-8.

26 Thureen PJ, Melara D, Fennessey PV, et al. Effect of low versus high intravenous amino acid intake on very low birth weight infants in the early neonatal period. Pediatr Res 2003:53:24-32.

27 Clark RH, Chace DH, Spitzer AR, et al. Effects of two different doses of amino acid supplementation on growth and blood amino acid levels in premature neonates admitted to the neonatal intensive care unit: a randomized, controlled trial. Pediatrics 2007;120:1286-96.

28 Blanco CL, Gong AK, Schoolfield J, et al. Impact of early and high amino acid supplementation on ELBW infants at 2 years. J Pediatr Gastroenterol Nutr 2012;54:601-07

29 Hulzebos CV, Sauer PJ. Energy requirements. Semin Fetal Neonatal Med 2007;12:2-10.

30 Catzeflis C, Schutz Y, Micheli JL, et al. Whole body protein synthesis and energy expenditure in very low birth weight infants. Pediatr Res 1985;19:679-87.

31 Beaufrere B. Protein turnover in low-birth-weight (LBW) infants. Acta Paediatrica Supplement 1994;405:86-92.

32 Beaufrere $B$, Fournier $V$, Salle $B$, et al. Leucine kinetics in fed low-birth-weight infants: importance of splanchnic tissues. Am J Physiol 1992;263(2 Pt 1):E214-20.

33 Koletzko B, Goulet O, Hunt J, et al. 1. Guidelines on Paediatric Parenteral Nutrition of the European Society of Paediatric Gastroenterology, Hepatology and Nutrition (ESPGHAN) and the European Society for Clinical Nutrition and Metabolism (ESPEN), Supported by the European Society of Paediatric Research (ESPR). J Pediatr Gastroenterol Nutr 2005:41(Suppl 2):S1-87.

34 Vlaardingerbroek $\mathrm{H}$, Veldhorst MAB, Spronk $\mathrm{S}$, et al. Parenteral lipid administration to very-low-birth-weight infants-early introduction of lipids and use of new lipid emulsions: a systematic review and meta-analysis. Am J Clin Nutr 2012;96:255-68.

35 Simmer K, Rao SC. Early introduction of lipids to parenterally-fed preterm infants. Cochrane Database Syst Rev 2005;(2):CD005256.

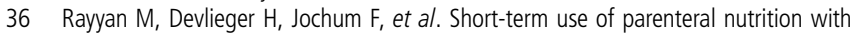
a lipid emulsion containing a mixture of soybean oil, olive oil, medium-chain triglycerides, and fish oil: a randomized double-blind study in preterm infants. JPEN J Parenter Enteral Nutr 2012:36(1 Suppl):81S-94S.

37 Deshpande GC, Simmer K, Mori T, et al. Parenteral lipid emulsions based on olive oil compared with soybean oil in preterm (\&lt;28 weeks'Gestation) neonates: A randomised controlled trial. J Pediatr Gastroenterol Nutr 2009;49:619-25.

38 Gura KM, Lee S, Valim C, et al. Safety and efficacy of a fish-oil based fat emulsion in the treatment of parenteral nutrition associated liver disease. Pediatrics 2008;121:e678-e86.

39 Ryan AS, Montalto MB, Groh-Wargo S, et al. Effect of DHA-containing formula on growth of preterm infants to 59 weeks postmenstrual age. Am J Hum Biol 1999:11:457-67.

40 Beardsall K, Vanhaesebrouck S, Ogilvy-Stuart AL, et al. Early insulin therapy in very-low-birth-weight infants. N Engl J Med 2008:359:1873-84.

41 Lofqvist C, Engstrom E, Sigurdsson J, et al. Postnatal head growth deficit among premature infants parallels retinopathy of prematurity and insulin-like growth factor-1 deficit. Pediatrics 2006;117:1930-38.

42 VanderVeen DK, Martin CR, Mehendale $R$, et al. Early nutrition and weight gain in preterm newborns and the risk of retinopathy of prematurity. PLOS ONE 2013;8:e64325.

43 Moltu SJ, Strommen K, Blakstad EW, et al. Enhanced feeding in very-low-birth-weight infants may cause electrolyte disturbances and septicemia-a randomized, controlled trial. Clin Nutr 2013;32:207-12.

44 Bishop NJ, Morley R, Day JP, et al. Aluminum neurotoxicity in preterm infants receiving intravenous-feeding solutions.[comment]. N Eng/ J Med 1997;336:1557-61.

45 Fewtrell MS, Bishop NJ, Edmonds CJ, et al. Aluminum exposure from parenteral nutrition in preterm infants: Bone health at 15-year follow-up (Pediatrics (2009) 124, 5 (1372-1379)). Pediatrics 2009:124:1709.

46 Lewandowski AJ, Augustine D, Lamata P, et al. Preterm heart in adult life: Cardiovascular magnetic resonance reveals distinct differences in left ventricular mass, geometry, and function. Circulation 2013;127:197-206. 